\title{
El «escándalo de la filosofía». El problema de la realidad y su «disolución»*
}

\author{
GOTTFRIED GABRIEL \\ Universidad de Bochum
}

En las tradiciones más dispares de la filosofía de la praxis (desde Marx hasta Heidegger), el problema de la realidad y la contraposición entre el idealismo y el realismo epistemológicos que le va asociada constituyen la expresión de una relación alienada con el mundo. Dicho problema fue desechado con fundamentos muy distintos, pero con un resultado semejante, por representantes de la teoría de la ciencia (Carnap), quienes lo consideraron un "problema aparente". Partiendo de los análisis de Schopenhauer $\mathrm{y}$ Wittgenstein sobre la temática de la alienación y el solipsismo, se tratará aquí no tanto de contraponer las posiciones del realismo y del idealismo como enunciados en conflicto, sino de conferirles el estatus de visiones del mundo que han de combinarse en cuanto aspectos complementarios de la humana conditio.

\section{Estado del problema}

El problema de la realidad es un problema disputado, y esto no quiere decir únicamente que se trate de un problema reñido, de un problema en torno al cual se producen disputas, sino, sobre todo, que es su carácter mismo de problema lo que se halla en cuestión. Hay, en efecto, quienes opinan que el problema de la realidad no es un problema real, sino - según se afirma reiteradamente- una apariencia de problema. Para ellos, lo es desde luego cuando, al formularlo, uno se pregunta por la existencia de un mundo exterior cuyo ser resulte independiente del sujeto cognoscitivo. Pero las dificultades comienzan en el momento mismo de expresar con exactitud lo que esto quiere decir.

Antes que nada, conviene hacer una distínción importante: por "ser" no se entenderá aquí el "ser-así" (el modo de ser), sino el "ser-ahí (la existencia). La distinción es crucial, porque permite atribuir al mundo exterior una existencia, un ser-ahí independiente, sin con ello afirmar que dicho

\footnotetext{
* "Der 'Skandal der Philosophie'. Das Realitätsproblem und seine 'Lösung." Traducción castellana de Antonio Valdecantos Alcaide. En lo que sigue se reúnen reflexiones que aparecerán próximamente en forma más amplia y detallada en mi libro Gninatmobleme der Erkentnistheorie. Von Descartes zu Witgenstein, Paderborn, 1993.
} 
mundo exterior se halla formado, en su ser-así, tal como a nosotros se nos manifiesta. A este respecto, se podría dar por sentado que el sujeto desempeña una contribución esencial a la constitución del mundo en su ser-así, ya sea que se limite a las llamadas cualidades secundarias (Locke), ya sea que se le atribuyan también las cualidades primarias en cuanto formas de la intuición y categorias del entendimiento (Kant). El qué de la existencia puede, por tanto, depender en mayor o menor medida del sujeto cognoscente, pero el qué de la existencia se mantiene independiente del sujeto, al menos para todos aquellos filósofos a los que se califica de "realistas" por contraposición a los llamados uidealistas». Después de lo hasta ahora dicho, no debería sorprender que incluso un «idealista trascendental» como Kant sea acreedor a la denominación de realista en lo tocante a la pregunta por la existencia del mundo exterior. La independencia de éste, según Kant, está garantizada por la cosa en sí. Podría decirse que el idealismo kantiano es un idealismo del ser-así, no del ser-ahí. Un idealismo del ser-ahí lo hallamos, por el contrario, en la filosofia de Berkeley, donde el ser-así de la cosa de halla "dado" independientemente del sujeto y no estấ "co-constituido" por medio del sujeto. Berkeley se mantiene plenamente dentro de la tradición empirista en lo tocante a la cuestión del ser-así, pero no en lo relativo a la cuestión del ser-ahí. A lo que se refiere, en efecto, esse en el principio berkeleyano esse est percipi es al ser-ahi de la cosa, no a su ser-así.

Ha de subrayarse que la posición de Berkeley no conduce de ningún modo al escepticismo o a un ilusionismo según el cual la totalidad del llamado mundo exterior constituyese una mera apariencia. Un mundo exterior fenoménico es algo que la mayor parte de las veces se reconoce expresamente. Un teórico idealista del conocimiento no dudará nunca de que allí hay una mesa, y la disputa entre el realismo y el idealismo no versará sobre el ser o el no ser de cosas determinadas. La cuestión no es aquí el ser o el no ser, sino lo que significan "ser" y "no ser".

Conviene no pasar por alto el hecho de que el problema de la realidad se introduce en la filosofía moderna como una secuela de las reflexiones escépticas. Este origen dejó huella en su devenir posterior. Recordemos que el problema surge, al hilo de la duda metódica cartesiana, a causa de que el Yo de las Meditaciones emprende paso a paso una retirada a su interioridad. La duda comienza con el engaño de los sentidos en ámbitos lejanos, se adueña de los objetos de los ámbitos próximos y, después, del cuerpo propio; y, al fin, el mundo exterior se hunde como un mundo de sueños, hasta que la totalidad del Yo se revela en sí misma como un ser que piensa, lo que aquí quiere decir un ser que duda. En el marco de la relación sujeto/objeto, esta retirada a la interioridad puede describirse señalando que los objetos posibles de conocimiento del sujeto cognoscente quedan reducidos a la nada. La duda sólo llega a suscitarse cuando el sujeto se convierte en objeto de conocimiento. Con ello se otorga al auto- 
conocimiento una posición de primacía, frente a la cual es el conocimiento del mundo exterior lo que debe probarse que está fundamentado. Tras la retirada a lo interior, es preciso conquistar lo exterior de nuevo. Así, el problema de la realidad se plantea desde sus comienzos como el problema de cómo enfrentarse a la duda sobre la realidad del mundo exterior.

Pues bien; en la historia de la filosofía no ha habido nadie en absoluto que se haya negado a reconocer un mundo exterior de carácter cuando menos empírico o fenoménico; aunque siga siendo objeto de disputa su naturaleza ontológica: si ese mundo exterior ha de determinarse o no como algo material. Un problema ulterior es el de aquello en que se funda el reconocimiento del mundo exterior: si en la creenicia o en el saber. Así, Kant consideró un "escándalo de la filosofía" el que la realidad del mundo exterior hubiera de admitirse "meramente en virtud de la creencia», ${ }^{1} \mathrm{y}$, consecuentemente, se dispuso a buscar una prueba de dicha realidad. Heidegger, por su parte, esgrimió contra Kant y la tradición la idea de que el escándalo no radica en no poseer prueba alguna, sino en la propia búsqueda de una tal prueba. ${ }^{2}$ Dicho en forma enfática: la duda metódica cartesiana, que, con su "búsqueda» de prueba, conduce a la separación de res extensa y res cogitans habría de ser rechazada de principio. La búsqueda de la certeza constituye el pecado original filosófico que, mediante la separación de sujeto y objeto, expulsó al hombre del "paraíso» de la unidad del mundo vital, arrojándolo hacia lo extraño, hacia la alienación.

Característico del tratamiento del problema en la filosofía moderna es, pues (y lo es desde Descartes), no sólo la propia pregunta por la existencia, sino también la pregunta por el modo epistémico del reconocimiento de la existencia: si éste ha de ser un modo del saber o tan sólo un modo del creer. Y deberíamos añadir igualmente que el saber no es eo ipso algo superior a la creencia, como sugiere la expresión kantiana - y también la del lenguaje usual. El confiar en algo es también una creencia, pero no una "mera» creencia, no un modo deficiente del saber. Aquí la tradición presenta alianzas sorprendentes que desafían los límites acostumbrados: en el bando del saber, hallamos a R. Descartes, a I. Kant, a G.E. Moore; en el bando del creer, a D. Hume, a F.H. Jacobi, a L. Wittgenstein.

Si el problema de la realidad camina de la mano con aspectos del problema de la alienación, es natural concebir su disolución como la superación de dicha alienación. A esta temática quisiera dedicarme en lo que sigue.

\section{¿Es el problema de la realidad una apariencia de problema?}

Al reconstruir el desarrollo histórico del problema de la realidad, se comparte desde casi todos los frentes la suposición de que los puntos de vista que a propósito suyo han ido sosteniéndose son de índole proposicional. Esto significa que el realismo y el idealismo pueden formularse en forma 
de enunciados susceptibles de verdad, que dichos enunciados se contradicen unos a otros y que, por ello, uno de los dos puntos de vista ha de llevar razón, y sólo uno de ellos puede llevarla, aunque quizá a esa posición le falte todo tipo de prueba. Desde una posición de crítica de la metafísica, ese supuesto fue combatido del modo más resuelto por R. Carnap.

La argumentación de Carnap puede resumirse como sigue: no cabe imaginar situación alguna en la que pudiera verificarse (probarse) o falsarse (refutarse) empíricamente el punto de vista del realismo o el del idealismo. Así pues, ni el enunciado del realista ni el del idealista se refieren a cosa alguna, y esto quiere decir que ambos enunciados carecen de sentido y que el problema de la realidad es una apariencia de problema:

[...] la ciencia no puede adoptar una posición en la pregunta por la realidad ni para contesiarla a favor ni en contra, porque la pregunta carece de sentido. ${ }^{3}$

Carnap tiene seguramente razón en su constatación de que las montañas con que el realista se encuentra en este mundo no son distintas de aquéllas con que se topa el idealista. De ahí que ni los enunciados del realista ni los del idealista sean proposiciones científicas, empíricamente contrastables. El conocimiento de lo anterior constituye un progreso en la tradición empirista. Segun Locke, la experiencia nos enseña que hay substancias materiales, con lo cual la tesis del realismo sería una proposición empíricamente verdadera, ${ }^{4}$ y esta errónea apreciación llegó hasta GE. Moore.

Aunque el asunto no se refiera a enunciados empíricos, no por ello se desvanece la cuestión de si, con respecto a las posiciones del realismo y el idealismo, nos enfrentamos con enunciados cuya verdad ha de fundarse de modo distinto al empírico, o si no nos las habemos en absoluto con enunciados, sino más bien con proferencias con sentido, aunque de un tipo ilocucionario distinto. Pero al veredicto de Carnap cabe objetarle sobre todo que la formulación de un criterio general de sentido es imposible. Dicho de otro modo: toda formulación de ese tipo ha de expresar inevitablemente qué es lo que decide si ella está «dotada de sentido». En particular, cs la aplicación sobre sí mismos de los criterios generales de sentido lo que hace que estos se conviertan en algo carente de sentido (según succde con Hume y Carnap). Un paso conocido en la dirección de esta autodisolución lo emprendió como es sabido Wittgenstein en el Tractatus, llevándolo al extremo con su célebre metáfora (6.54).

Si se los examina someramente, hay grandes coincidencias entre Carnap y Wittgenstein, pero es posible que no se perciba una diferencia decisiva. Mientras Carnap se enfrenta a lo que califica de problema aparente con el establecimiento de una "orden de desescombro" epistemológica que allane el camino de progreso de la ciencia, Wittgenstein se conduce como un terapeuta conocedor de que él mismo no está libre de la «enfermedad» 
metafísica que procura curar. Para Wittgenstein, los problemas aparentes tienen una dimensión antropológica comparable a la que posee la concepción kantiana de la metafísica como una «disposición natural» de la razón humana. En lo que sigue, trataré de defender este enfoque del problema de la realidad. Para ello me servirán como punto de partida las reflexiones de Wittgenstein.

\section{El solipsismo contemplativo de Wittgenstein}

Wittgenstein dio un paso decisivo al sostener que la filosofia no consiste en cnunciados susceptibles de verdad, necesitados de fundamentación. Aun si este paso es demasiado radical, de él no se sigue que la filosofía haya de convertirse en algo superfluo. Visto positivamente, lo anterior ofrece aclaraciones categoriales que deben conducir a una visión correcta del mundo, y esta comprensión es sustancialmente distinta del propósito lógico-científico de Carnap. La crítica del conocimiento que lleva a cabo el análisis lógico y lingüístico da un giro después del cual resulta decisiva la exigencia de no representar proposicionalmente (mediante proposiciones afirmativas bien formadas desde el punto de vista de la sintaxis lógica) la visión del mundo que se quiere lograr. Wittgenstein califica en el Tractatus su visión como solipsismo, como una respuesta singularmente extrema, por tanto, a la pregunta sobre la realidad. En forma característica, niega al mismo tiempo que quepa expresar el solipsismo en proposiciones con sentido:

5.62* En rigor, lo que el solipsismo entiende es plenamente correcto, sólo que eso no se puede decir, sino que se muestra. ${ }^{6}$

Como todas las demás reflexiones del Tractatus, también la concepción wittgensteiniana del solipsismo está inmersa en el contexto de la pregunta por la forma general de la proposición. Igual sucede con el problema del yo, al menos en el tránsito del 5.54 al 5.541. Aquí la pregunta estriba en si las proposiciones de la forma "A cree que $p$ » podrían dar ocasión a establecer la concepción veritativo-funcional del lenguaje sobre la que se está discutiendo. Wittgenstein lo niega, de un modo sin duda no convincente. (Aquí queda puesto sobre el tapete el problema de los hoy llamados contextos intensionales.) Pero el aspecto que importa para nuestra temática es tan sólo el resultado del análisis de Wittgenstein. Su argumentación concluirá en que, en tales proposiciones, el sujeto $A$ de que se habla es complejo y no simple, porque él mismo es un hecho. Se sigue entonces la proposición:

\footnotetext{
* Ésta y las siguientes citas del Tractatus se dan por la versión de Jacobo Muñoz e Isidoro Reguera! L. Wittgenstein, Thactatus logico-philosophicus (Madrid, Alianza, 1986). [N. del T.]
} 
5.5421 Esto muestra también que el alma -el sujeto, etc,-, tal como es concebida en la actual psicología superficial, es una quimera.

Un alma compuesta no sería ya, ciertamente, un alma.

La segunda proposición podría malinterpretarse apresuradamente, como si Wittgenstein exigiera a una psicología adecuada, no «superficial», que tratase al alma como algo no compuesto y, por tanto, simple. Lo que se está dando a cntender, por el contrario, es que en la ciencia empírica de la psicología no hay en absoluto lugar para un alma simple: la psicología habría de tratar, en calidad de hechos, con compuestos psíquicos. Dado que ello es así - y esto es lo que a Wittgenstein le importa-, se le prohíbe a dicha ciencia toda pretensión general de tratar acerca del «alma». La psicología empírica ha admitido esta objeción —que Wittgenstein no ha sido el único en suscitarle- cuando hoy, siguiendo una frase de éxito, se autocomprende con razón como una "psicología sin alma». Para Wittgenstein, sin embargo, el tema del alma, del sujeto, etc. —este es el segundo aspecto de su dictamen- no constituye en absoluto algo que esté filosóficamente «acabado»; la consecuencia es, más bien, que la cuestión ha de acometerse de manera no psicológica. El resultado de las reflexiones sobre el solipsismo lo deja claro:

5.641 Existe, pues, realmente un sentido en el que en filosofía puede tratarse no-psicológicamente del yo [el subrayado es mio, G.G.].

Aunque Wittgenstein se pronuncie contra la comprensión del alma cono objeto complejo, no es lícito ver aquí una reivindicación del alma como objeto simple (en el sentido, acaso, de la res cogitans cartesiana). No se trata, por tanto, de decidir qué tipo de objeto sea el alma. El asunto capital estriba en que el alma no es en absoluto un objeto. Los objetos lo son en esencia porque ocurren como objetos posibles en estados de cosas, y por ello pertenecen al mundo. Pero el sujeto de Wittgenstein no es una parte del mundo. La continuación del pasaje reza como sigue:

5.641. El yo entra en la filosofia por el hecho de que «el mundo es mi mundom.

El yo filosófico no es el hombre, ni el cuerpo humano, ni el alma humana, de la que trata la psicología, sino el sujeto metafísico, el límite - no una parte del mundo.

Y a estas consideraciones les sigue la proposición 6 con la definición de la forma general de la proposición. La inclusión de la temática del solipsismo en una problematización hipotética de la concepción veritativofuncional del lenguaje tiene sin duda que ver con el rechazo de una posible ocasión de peligro para la concepción extensionalista del lenguaje propia del Tractatus. Sería, sin embargo, un error acometer el tema del solipsismo 
sólo desde una perspectiva interior a la semántica. Para Wittgenstein, la expresión de los problemas de la vida conforma problemas filosóficos "serios», y su propio problema es el problema del yo, cuya disolución hace coincidir con la «correcta» acomodación del sujeto al mundo de los hechos. Por lo hasta aquí visto, deberíamos más bien afirmar que la concep" ción del lenguaje del Tractatus "casa" perfectamente con la concepción wittgensteiniana del sujeto. Análogamente, habriamos de esperar que la concepción modificada del lenguaje de las Investigaciones filosóficas tenga que ver sustancialmente con que la "disolución" a que se aspiraba no sc produjo en realidad.

Esforcémonos en primer término por comprender lo que "entiende» el solipsismo. Aquí no deberíamos perder de vista el hecho de que Wittgenstein no es simplemente un lógico o un filósofo del lenguaje, sino un pensador existencial para quien la lógica y el análisis del lenguaje servían como medio metódico a un fin más amplio, a un fin ético-estético. Este es el sentido en que ha de comprenderse el solipsismo.

Hemos de hacernos cargo, por consiguiente, de que el solipsismo de Wittgenstein no es el solipsismo metódico de Descartes, sino el solipsismo contemplativo de Schopenhauer, aquel al que se caracteriza como un "estado de la pura objetividad de la intuición» (W, II, p. 475) ${ }^{7}$ del modo siguiente:

Quien [...] se ha abismado y desvanecido en la intuición de la naturaleza tanto que ya sólo existe como un puro sujeto que conoce se convierte de modo inmediato en la condición, en el soporte del mundo y de toda existencia objetiva, pues ésta se presenta de ahí en adelante como dependiente de la suya propia. Él compromete a la naturaleza en sí de tal modo que la siente tan sólo como un accidente de su propia esencia [W, I, p. 260].

Este recogimiento del objeto en el sujeto equivale, según Schopenhauer, a una superación ética de la escisión sujeto/objeto. En cuanto superación asimismo estética, le corresponde una entrega del sujeto al objeto "en la que [aquel] se desvanece por entero en el objeto intuido" (W, I, p. 260). En el solipsismo de Wittgenstein, ambos momentos son uno solo. Precisamente de este modo es menester entender la proposición «ética y estética son una y la misma cosa» (6.421).

El punto de partida de la «disolución» wittgensteiniana del problema de la realidad es el método (descrito en 5.631) «para aislar el sujeto», que conduce a una escisión del yo empírico y el sujeto trascendental, ya que todos los rasgos peculiares del sujeto empírico (desde el cuerpo hasta las representaciones, pasando por las inflexiones de la voluntad) se convierten en la autoobservación en datos de tipo objetivo. El sujeto empírico se convierte él mismo en objeto. Este "método" adelgaza, por así decir, al sujeto en beneficio del objeto, desplaza al sujeto empírico hacia el objeto, hasta 
que lo único que queda del sujeto es un punto de vista que "coordina» la realidad: el sujeto de un solipsismo trascendental o el «eterno ojo del mundow de Schopenhauer (W, II, p. 479 ) que no se ve a sí mismo. ${ }^{8}$ Wittgenstein define el resultado como la coincidencia del solipsismo «llevado a sus últimas consecuencias" con el "puro" realismo:

5.64 El yo del solipsismo se contrae hasta convertirse en un punto inextenso y queda la realidad con él coordinada.

No podemos por menos que denominar esquizofrenia al peligro de un tal distanciamiento respecto del cuerpo propio. Es digno de señalarse el que también Schopenhauer extendiera la contemplación hasta el distanciamiento con respecto al propio cuerpo cuando, en la acción, es testigo de sí mismo xdesde fuera» (W, II, p. 480). ¿Qué es lo que de positivo está en juego aquí? Schopenhauer describe el contemplativo «estado de la objetividad pura de la intuición" como "algo que hace totalmente feliz" (W, II, p. 475). De la misma manera hay que entender a Wittgenstein. El mundo de lo contemplativo es el mundo de lo feliz. Se distingue del mundo de lo desdichado, no en que en él lo que es el caso sea de otra manera, sino sólo en que él -como un todo- es visto de otra manera (cf. Tractatus, 6.43). La diferencia no radica, pues, en los hechos, sino únicamente en la acomodación del sujeto respecto de ellos. ${ }^{9}$ El mundo de lo feliz, considerado como un hecho, es el mismo mundo que el de lo desdichado (visto como mi mundo, esto es, bajo la superación de la alienación distanciadora). Aquí también soy testigo quizá de mi cuerpo desde fuera; pero testigo impasible, con la mirada puesta en aquello que mi cuerpo piensa que le es tan ajeno. "El mundo tal como yo lo encontré" se convierte en mi mundo cuando yo lo tomo como es. No por ello está excluido el obrar con arreglo a una buena o mala volición, pero es feliz quien, por el contrario, concibe el logro de su volición como idéntico a un «don», quien quiere lo mejor sin quejarse cuando no logra lo mejor. Nos encontramos aquí con una radicalización de la ética kantiana de la intención según la cual nada es bueno sino la buena voluntad. El mundo mismo «es independiente de mi volun$\operatorname{tad}$ " (6.373).

El nexo entre la vida feliz y el solipsismo puede exponerse sucintamente señalando que el yo empírico debe adoptar el punto de vista del sujeto trascendental a pesar de los hechos adversos del mundo. Cuando se nos haga claro que la felicidad de una vivencia solipsista de unidad es singular y momentánea, como Schopenhauer destaca de manera «realistan, entonces ya no esperaremos poder vivir largamente esa vida feliz.

El mundo del Tractatus es un mundo momentáneo, y con ello condice el hecho de que, desde el punto de vista semántico, el prototipo de los objetos del mundo esté formado por analogía con los momentos espacio- 
temporales del campo visual. ${ }^{10}$ Un mundo momentáneo, y tanto más el mundo del momento feliz, no tiene duración, no puede conservarse en forma perdurable. En general, la vivencia del solipsismo posee un rostro jánico. Una fase feliz (eufórica) está siempre amenazada por su "reflujo» en una fase desdichada (depresiva). Quien conoce el solipsismo, conoce también su lado oscuro. Señala Schopenhauer:

Bueno es para cada uno el estado en que él es todas las cosas [cuando solipsismo y realismo coinciden, G.G.], pero jay cuando es exclusivamente uno! [W, M, p. 479].

Wittgenstein parece no haber tomado demasiado en serio esta advertencia, empeñándose en un "punto de vista estrictamente solipsista" ${ }^{11}$ que se refiere a un solipsismo contemplativo entendido como estado permanente. ${ }^{12}$ Ciertamente, Wittgenstein se había ocupado no poco de la cuestión; su biografía da sobrado testimonio.

\section{Crítica wittgensteiniana del solipsismo metódico}

El desmoronamiento de su concepción del mundo solipsista contemplativa tan largamente acariciada dio ocasión a Wittgenstein para plantear de nuevo la pregunta por la vida feliz. El tránsito del Tractatus a las Investigaciones filosóficas es, en primer término, el tránsito hacia una nueva comprensión de lo que sea una vida lograda, idea esta que se viene abajo al modificar la concepción del lenguaje. Al tránsito de una forma general de la proposición a los muchos juegos de lenguaje concretos, de la forma lógica a las formas de vida, le va asociado el intento de superar la escisión sujeto/objeto mediante la praxis en lugar de mediante la contemplación.

Esta idea vincula la filosofía wittgensteiniana de las formas de vida con las distintas filosofías de la praxis, cuyo espectro abarca desde Marx ${ }^{13}$ hasta Heidegger. ${ }^{14}$ En esta tradición, por heterogéncos que sean sus miembros en otros aspectos, el problema de la realidad se ha considerado comúnmente como expresión y síntoma de la alienación. Aunque las causas dc la alienación se ubiquen en ámbitos diferentes, en todos los casos es su superación lo que se quiere lograr. El estado de alienación se señala en última instancia como algo negativo - a diferencia de la interpretación "romántica» de Schopenhauer-, aunque, al menos a veces, se lo considere un estadio de tránsito evolutivo. Habría que recordar, por cierto, a este propósito, que Descartes describe también el estado de duda total en vocabulario de alienación -como la alienación de Dios. La hipótesis de un Dios falaz no expresa nada distinto del ausentarse de Dios. En tanto es preciso superar dicho estado, las diferencias se refieren al modo como dicha superación haya de producirse: si por medio de la filosofía de la 
conciencia, de la economía política, de la ontología existencial o de la crítica del lenguaje.

El objeto de la crítica wittgensteiniana es (como en Heidegger) el solipsismo metódico de Descartes y con él la totalídad de la tradición de la teoría del conocimiento moderna orientada a la noción del saber, de cuyo error, según Wittgenstein, el problema de la realidad constituye la culminación. Esta tradición puede describirse señalando que convierte a lo psíquico - considerado como lo psíquico propio- en el punto de partida de la problemática epistemológica. A lo psíquico propio se le otorga una posición metódicamente predominante no sólo en el racionalismo de Descartes, sino también en el empirismo de Locke. Si yo tengo una idea de lo verde, una y otra tradición afirmarán de consuno dos cosas: que yo eso lo sé sin lugar a dudas y que soy sólo yo quien sabe eso que es indudable. Un solipsismo metódico latente sostiene a la entera epistemología moderna.

El solipsismo metódico implica que no sólo el saber de lo físico, sino también el del mundo psíquico exterior, el saber, por tanto, que yo poseo de mis semejantes (de lo psíquico ajeno) se presenta como un saber derivado. Por ello, la relación que el hombre tiene consigo mismo se califica, según el punto de partida metódico del solipsismo, como una autocerteza que puede saberse. Es aquí donde Wittgenstein parece detectar la fuente de una relación falsa (alienada) del hombre consigo mismo, con los otros hombres y con el mundo. En el marco de la llamada crítica del lenguaje privado (Investigaciones, \$ $243 \mathrm{ss}$.), pondrá en tela de juicio la idea de que poseemos un saber de lo psíquico propio precisamente tratando de mostrar mediante el análisis del lenguaje que el relacionar la palabra "saber» con lo psíquico propio constituye un mal uso de esa palabra:

¿Hasta qué punto son mis sensaciones privadas? - Bueno, sólo yo puedo saber si realmente tengo dolor; el otro sólo puede presumirlo. - Esto es en cierto modo falso y en otro un sinsentido. Si usamos la palabra "saber" como se usa normalmente (iy cómo si no debemos usarla!) entonces los demás saben muy frecuentemente cuándo tengo dolor. -Sí, ipero no, sin embargo, con la seguridad con que yo mismo lo sé! - De mí no puede decirse en absoluto (excepto quizá en broma) que sé que tengo dolor. ¿Pues qué querrá decir esto, excepto quizá que tengo dolor? [Investigaciones filosóficas, $\$ 246$ ]. ${ }^{15}$

De este modo, es preciso abandonar lo psíquico propio como paradigma de lo que puede saberse y como punto de partida para el reconocimiento de formas más amplias de saber, pero no para ponerlo en duda a la manera escéptica, sino precisamente para dejarlo a salvo de la objetivación del saber. Y la crítica al solipsismo metódico no se dirige ni siquiera contra su idea de un acceso privilegiado al propio yo, sino contra la pretensión de que dicho acceso pueda tener éxito por medio del saber, contra el supuesto de que el privilegio haya de manifestarse como saber. Witt- 
genstein amplía estas reflexiones finalmente (en Sobre la certeza) a una crítica general del cercioramiento científico sobre el mundo estableciendo una nucva relación entre creer y saber en virtud de la cual lo primero adquirirá una posición preponderante sobre lo segundo.

¿Cómo hemos de entender y de sacar provecho de la crítica de Wittgenstein a la epistemología moderna? La temática de dicha tradición, que sólo se mantiene con la tensión entre sujeto y objeto o con la escisión de sujeto y objeto, ¿no está acaso falta de fundamento?, ¿debemos, entonces, "librarnos" de una vez por todas de esa especie de pecado filosólico original ${ }^{16}$ Dicho de un modo todavía más general: ¿nos encontramos en los escritos de Wittgenstein con esa osadía de una disolución de la llamada razón occidental «centrada en el sujeto»?

Desde luego, la relación de Wittgenstein con la modernidad estriba en que él se nos muestra como un crítico de la razón moderna y, por ello, como adversario de una Ilustración meramente científica. Esto se hace claro precisamente en su establecimiento de la relación entre creencia y saber, que lo vincula sorprendentemente a críticos tempranos de la Ilustración como Hamann y Jacobi. Pero, en su perspectiva, el pensar centrado en el sujeto no aparece en términos genéricos, sino solamente en la medida en que formula una pretensión general de fundamentación. Con ello se dibuja una alternativa no sólo a la crítica de la llamada postmodernidad al sujeto racional, sino también a toda tentativa de salvamento de la razón a costa del sujeto: ahora seguimos aferrados a él, sólo que con fundamento distinto. Nada hay de malo en el sujeto salvo su interpretación como algo que sabe sobre sí mismo. Pero hay que recordar que el solipsismo del Tractatus no era un solipsismo metódico, sino un solipsismo contemplativo. De ahí que la crítica de las Investigaciones filosóficas al solipsismo, que se refieren a un solipsismo metódico, no afecten al solipsismo contemplativo del Tractatus.

\section{Sobre la complementariedad de realismo e idealismo}

Para una apreciación más adecuada de la autocrítica de Wiltgenstein, tomaremos como punto de partida el fenómeno de la «habitación visual» (Investigaciones, $\S 398$ ss.). En su descripción de esa "nueva sensación», Wittgenstein previene de antemano contra el interpretar la adopción de una visión contemplativa como la visión de objetos nuevos, como la visión, por ejemplo, de unos llamados datos sensoriales capaces de constituir «la materia prima del universo" ( $\$ 401$ ). El peligro estriba en interpretar los datos sensoriales de manera fundamentalista como si fuesen objetos simples, y de ese modo el conjunto del mundo estuviera estructurado por ellos. Así es como fueron entendidos, de hecho, en gran parte, en la nueva epistemología analítica desde G.E. Moore y B. Russell, donde adoptaron el 
papel de las «ideas» (Locke, Berkeley) e «impresiones» (Hume) de la percepción externa. Una incesante discusión se ha seguido sobre el estatus de los datos sensoriales, sobre si se trata de objetos "privados" o "públicos", de formaciones psíquicas propias o de partes de la superficie de los objetos materiales. En esta discusión, los datos sensoriales se conciben como los elementos básicos inmediatamente dados a partir de los cuales ha de constituirse el mundo exterior, coincidiendo con la tradición en que la introducción de los datos sensoriales halla su punto de partida en el fenómeno de la llamada ilusión sensorial. Se suele aludir al hecho de que con frecuencia pensamos que percibimos objetos que cn realidad no existen $o$, más anodinamente, se recuerda que la apariencia de los objetos puede variar según ciertas circunstancias (perspectiva, luz y sombra, etc.). Como la mayor parte de las veces las percepciones no reproducen, en efecto, los objetos tal como éstos son realmente, se concluye que lo percibido en tales casos no puede coincidir con los objetos mismos. Como objetos sustitutivos se introducen ahora los datos sensoriales, aunque esto se lleve a cabo por medio del controvertido tránsito de "parecer que se percibe un $x$ » a "percibir un $x$ aparentes. ${ }^{17} \mathrm{El}$ caso de ilusión se generaliza apresuradamente: no es que percibamos las cosas de manera no inmediata, sino que lo único que se nos ofrece en realidad (como representantes de las cosas) son datos sensoriales.

Con todas sus diferencias, es común a las llamadas teorías de los datos sensoriales el realizar precisamente aquello contra lo que Wittgenstein prevenía, a saber, considerar los datos sensoriales como material de construcción del mundo o de su estructura lógica. Este papel fundante se les asigna porque se los considera "incorregibles». Como ya ocurría con las «ideas» o «impresiones» de la vieja tradición, los datos sensoriales se conciben de tal manera que, si bien no reproducen la realidad tal como es en sî —eso sería imposible-, no ofrecen ninguna duda respecto de su ser dado (como ser-así y ser-ahí). Esta concepción fue sometida a una crítica minuciosa por los filósofos analíticos del lenguaje ordinario. ${ }^{18}$ Lo único desconcertante sobre el particular es la introducción de los datos sensoriales en el contexto de las pretensiones de fundamentación, y no en el marco de las descripciones fenomenológicas, del modo, por ejemplo, como antes lo hemos intentado en las explicaciones de los fundamentos vivenciales del solipsismo. Distinguíamos allí dos formas de solipsismo a las que correspondían sendos modos de acomodación no-objetual al mundo (en particular en la visión): la acomodación positiva ("feliz") en la contemplación y la negativa ( desdichada") en la alienación.

En la medida en que la percepción puede constituir, dentro de la contemplación, un fin en sí mismo de carácter estético y se excluye así que la realidad de los objetos esté producida por una resistencia, puede decirse con cierto derecho que el contemplador representa perceptualmente los 
objetos de un modo no ob-jetual [gegen-ständlich], sino más bien como meros fenómenos (datos sensoriales) en el interior de su campo visual. Nótese que aquí no cumple hablar de percepción de los datos sensoriales, sino de percepción de los objetos como datos sensoriales. Con esto, nos sustraemos a la reflexión de Wittgenstein según la cual la contemplación ha de interpretarse "como la visión de un objeto nuevo" en el sentido no ya de ver un nuevo objeto, sino los objetos de una nueva manera. Para la alienación puede darse una aclaración análoga. En la contemplación, la objetualidad es ajena al tiempo, de modo que no puede lograrse hasta adelantarse a él. Las cosas se ven como después de un largo viaje aéreo, "como en una películan. La realidad se ve como película.

Ahora bien, en un sentido más amplio que Schopenhauer puso de manifiesto, la contemplación es también una forma de alienación. Aunque aquélla sigue siendo una contemplación «feliz» mientras la superación de la realidad se presente como una exclusión de la realidad en un elevado "estado de ánimo" estético y no como una aflictiva disolución de la realidad. Aquella pérdida que se experimenta como algo «desdichado» sólo se define como alienación cuando la necesidad práctica insiste en triunfar sobre la realidad sin que esto tenga éxito porque los objetos parecen rebelarse en su objetualidad. En cualquier caso, hay que recordar con Schopenhauer que el estado de alienación también lleva inherentes momentos positivos que liberan las posibilidades de conocimiento características del hombre.

A partir de este trasfondo, se nos abre la posibilidad de ver el problema de la realidad a una nueva luz, una vez eliminadas como malentendidos ciertas pretensiones cartesianas de fundamentación. No se trata en absoluto de que la escisión sujeto/objeto "se disipe», como suele decirse, y suceda lo propio con el sujeto - a la manera postmoderna- y finalmente -en una exageración panficcionalista- también con el objeto. La cuestión no estriba en si es el idealismo (el solipsismo) o el realismo quien lleva razón. ${ }^{19}$ Carnap había comprendido que ambas concepciones expresan un sentimiento vital diferente. Pero lo anterior da origen a una contradicción, pues - desde el punto de vista del empirismo lógico- ello implica sustraer el problema a la jurisdicción del conocimiento. Camap (con la tradición) parte de la idea de que el idealismo y el realismo se oponen el uno al otro proposicionalmente, que una postura es la negación de la otra en términos de la lógica de enunciados, y, bajo esta presuposición, desecha la pregunta en su totalidad como una pregunta aparente. Según nuestra interpretación (o reinterpretación) del problema de la realidad, el idealismo y el realismo no se refieren en absoluto a hechos en el mundo, sino a los modos de visión del mundo. Así sería posible que - según ocurre con dos obras de arte que representan modos contrarios de ver el mundopudieran coexistir el uno junto al otro sin excluirse: como aspectos mutua- 
mente complementarios de la conditio humana, como los complementarios modos de obrar propios del "trabajo" realista y del "ocio" contemplativo cuyo equilibrio habría de lograrse en esta vida.

Carnap acertó completamente al situar la oposición entre realismo e idealismo en el ámbito de la concepción práctica del mundo, pero se equivocó del todo cuando, por ese motivo, expulsó esta cuestión allende las fronteras de la actividad filosófica dotada de sentido.

\section{NOTAS}

1. I. Kant, Critica de la razon pura, B XXXXX.

2. M. Heidegger, El ser y el tiempo (trad. José Gaos), México, Fondo de Cultura Económica, 1971 .

3. R. Camap, Scheinprobteme in der Philosophie. Das Fremdpsychische und der Reatismusstreit, Berlín, 1928, §9.

4. CF. J. Locke, Investigación sobre el entendimiento humano, libro II, cap. XXW, ap. 29 (ed. Sergio Rábade y Esmeralda García), Madrid, Editora Nacional, 1980, p. 459.

5. Moore es de la opinión de que "se habría podido dar el caso de que el tiempo no fuera real, de que no lo fueran las cosas materiales o el espacio, de que no lo fuera cada uno de los yoes». Vid. G.E. Moore, "Defensa del sentido común", en Defensa del sentido común (introd. Javier Muguerza, trad, Carlos Solís), Madrid, Taurus, 1972. Uno se pregunta entre otras cosas qué es lo que con sentido debería querer decir aquí adarse el casos. El espacio y el tiempo son condiciones para que pueda darse el caso. Ha de constatarse, aquí como de costumbre, que Moore permaneció aciego* frente a las preguntas trascendentales.

6. Para entender la temática del solipsismo es obligada la lectura complementaria de pasajes muy expresivos de los Diarios de Wittgenstein.

7. Se cita por Sämfliche Werke, I-V (ed. W. von Löhneysen), 2. Aufl, StuttgartFrancfort, 1968 , señalando ' $\mathrm{W}$ y a continuación el númcro del volumen en romanos.

8. Wittgenstein compara la relación entre el sujeto y el mundo con la relación entre el ojo y el campo visual (5.633 y 5.6331). Ha de señalarse aquí el ejemplo de Emst Mach del hecho del campo visual (Analyse der Empfinfungen, 9." ed, Jena, 1922, reimpr. (con prólogo de G. Wolters), Darmstadt, 1985, cap. I, apartado 10), que se representa característicamente como aquello que el ojo ha de ver en un momento determinado. Pertenecen al campo visual las demás partes del cuerpo, excluido el ojo y otras partes del rostro.

9. En Schopenhauer, los objetos de la contemplación no son hechos sino ideas. Wittgenstein hace valer contra esto la acomodación contemplativa a los hechos, yendo así más lejos que Schopenhauer al considerar al propio mundo una obra de arte.

10. Así, la crítica retrospectiva de las Investigaciones filosóficas a la idea del objeto lógicamente simple del Tractatus está ligada a la comprensión de la expresión espacio-temporalmente independiente "esto" como el "nombre genuino» (Investigaciones, § 38). Ello se refiere aquí de manera directa al atomismo lógico de Russell, pero indirectamente también a la propia posición de Wittgenstein.

11. L. Wittgenstein, Geheime Tagebucher, 1914-1916 [Diarios secretos, 19141916], 8.12.1914. Vid. la traducción castellana de Andrés Sánchez Pascual en la revista Saber (Barcelona), 5 y 6 (1985).

12. En situaciones de alienación desesperada, Wittgenstein se acoge a la acomodación contemplativa: «Ahora sólo es necesaria una cosa: poder contemplar todo cuanto ocurra» (Diarios secretos, 25/8/1914; el subrayado es mío, G.G.). Wittgenstein se representá así la superación del estado vital referido: «Ayer me propuse no oponer ninguna resistencia, aligerar, por así decir, mi exterior y dejar tranquilo mi interion (26/8/1914). 
13. Véase por ejemplo la segunda de las Tests sobre Fenerbach: «La disputa sobre la realidad o no realidad de un pensar que se aisla de la praxis es una cuestión puramente escolástica".

14. Cf. M. Heidegger, El ser y el tiempo, cit., § 43.

15. L. Wittgenstein, Investigaciones filosóficas (trad. Alfonşo García Suárez y Ulises Moulincs), Barcelona/México, Crítica / Instituto de Investigaciones Filosóficas UNAM, 1988, p. 221.

16. Fichte escribe a Jacobi el 30 de agosto de 1795: "Comenzamos a filosofar con petulancia, y asi perdimos la inocencia; descubrimos nuestra desnudez y desde entonces filosofamos en busca de nuestra salvación” (J.G. Fichte, Bricfwechsel, ed. H. Schulz, Leipzig, 1930. reimpr. Hildesheim, 1967, vol. I, p. 502).

17. Cf. por ejemplo, A.J. Ayer, The Problem of Knowledge, Harmondsworth, 1956, pp. 96 ss.

18. CF. sobre todo J.L. Austin, Sinn und Simneserfahnung, Stuttgart, 1975 (en particular el Cap. X), y G. Ryle, Der Begriff des Geistes, Stuttgart, 1969, cap. 7, ap. 3.

19. El realismo es "verdadero" en cuanto su negación se interpretase como escepticismo o panficcionalismo. El idealismo es uverdaderon en cuanto no implica negación escéptica de la realidad, sino que consiste en la posibilidad de una actitud estético-contemplativa. 